In, "Electroactive Polymers and Rapid Prototyping"

Mat. Res. Soc. Symp. Proc. Vol. 698, 265-275 @ 2002 Materials Research Society

\title{
Direct Write Microbatteries for Next-Generation Microelectronic Devices
}

\author{
Karen E. Swider-Lyons, ${ }^{*}{ }^{*}$ Alberto Piqué, ${ }^{+}$Craig B. Arnold, ${ }^{+}$and Ryan C. Wartena* \\ "Code 6171 and ${ }^{+}$Code 6372 \\ Naval Research Laboratory \\ Washington, DC 20375-5342 USA \\ ¥karen.lyons@nrl.navy.mil
}

\begin{abstract}
Microbatteries and integrated microbattery systems are likely to be the sole power source or a power-source component for the next generation of microelectronic devices. As part of the LEAPS (Laser Engineering of Advanced Power Sources) program, custom-designed microbatteries and ultracapacitors will be integrated in microelectronic circuits for optimum performance. The Naval Research Laboratory's Matrix-Assisted Pulsed-Laser Deposition Direct-Write (MAPLE DW) process is used to rapidly fabricate various primary and secondary (non-rechargeable and chargeable) electrochemical power sources. This laser forward-transfer process can be used to transfer any type of battery material and battery material mixtures, including polymers, hydrated oxides, metals, and corrosive electrolytes. Additional laser micromachining capabilities are used to tailor the battery sizes, interfaces, and configurations. Examples are given for planar $\mathrm{RuO}_{2}$ ultracapacitors and stacked alkaline batteries.
\end{abstract}

\section{INTRODUCTION}

The trend in materials development programs is toward the miniaturization of electronics and devices. Yet, an important question has not yet been answered: what will be the power source for this next generation of micro- and nano-electronic devices?

We discuss in this manuscript why and how integrated microbatteries and ultracapacitors may be used in next-generation microelectronics, and show how a laser-based direct-write process, MAPLE DW, can make an impact on this growing field. As part of our LEAPS (Laser Engineering of Advanced Power Sources) initiative, primary and secondary microbatteries and micro-ultracapacitors will be fabricated and integrated into microelectronics. Examples are given for stacked alkaline batteries and planar $\mathrm{RuO}_{2}$ ultracapacitors.

\section{$\underline{\text { Battery overview }}$}

A schematic of a battery with a button-cell geometry is shown in Fig. 1. Every battery cell has seven major components: (A) positive electrode, (B) negative electrode, (C) separator, (D) electrolyte, (E \& F) current collectors, $(\mathrm{G})$ packaging, and $(\mathrm{H})$ interconnects to an electronic load. The composition of each component is a function of the battery chemistry (e.g., alkaline, lithium, etc.) and its chemical stability. See reference [1] for an overview of different battery chemistries. 

A: Positive electrode
B: Negative electrode
C: Separator
D: Electrolyte
E: Positive current collector
F: Negative current collector
G: Packaging

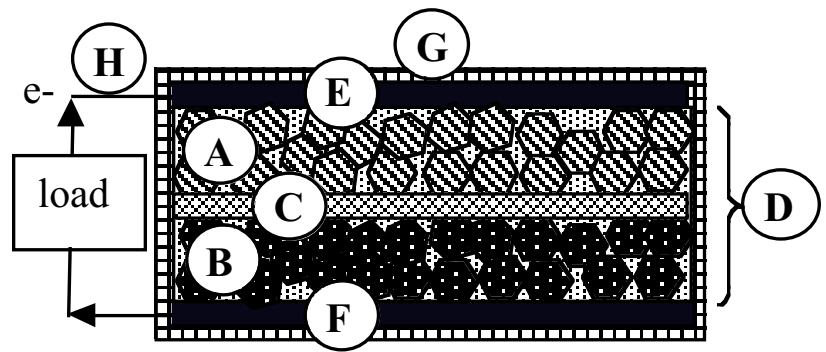

H: Interconnects

Figure 1. Schematic of the cross section of a battery cell.

Alkaline batteries typically have positive electrodes of "electrolytic $\mathrm{MnO}_{2}$ ", a defective hydrous manganese oxide $\left(\mathrm{MnO}_{2-\mathrm{x}} \bullet \mathrm{yH}_{2} \mathrm{O}\right)$ that is a mixed ionic/electronic conductor. Each $\mathrm{MnO}_{2}$ electrode is a composite of the electrolytic $\mathrm{MnO}_{2}$ for charge storage, high purity carbon for enhanced electronic conductivity, and a polymeric binder (e.g., polyvinylidene fluoride, PVDF). The negative electrode includes zinc powder, a binder, and also can contain carbon. The cathode and anode are electronically isolated with a porous separator, such as a woven polymer, that is interspersed with the ionically conducting $\mathrm{KOH}$ electrolyte. Potassium hydroxide is also mixed with the electrodes to improve their ionic conductivity. The current collectors evenly collect and insert the electrons into the battery negative and positive electrodes, respectively. Metal is preferred for packaging because it has high structural integrity, low permeability to water and gases, and can serve as an interconnect. Low-permeability polymers with high glass transition temperatures can also be used.

The cathode and anode charge and discharge electrons to power a load connected through an external circuit. The potential difference between the electrodes is a function of the natural differences in their thermodynamic potentials, plus several variables, such as the solution $\mathrm{pH}$ and charge-state of the materials. As the $\mathrm{MnO}_{2}$ in the positive electrode is charged, its oxidation state changes from $4^{+}$to $3^{+}$(Eq. 1). The $\mathrm{Zn}$ is oxidized as it is charged (Eq. 2). Similar equations describe Li battery chemistry, except the ion is $\mathrm{Li}^{+}$rather than $\mathrm{OH}^{-}$.

$$
\begin{aligned}
& \mathrm{MnO} \cdot(\mathrm{OH})_{x}+y \mathrm{e}^{-} \rightarrow \mathrm{Mn} \cdot(\mathrm{OH})_{x-y}+y \mathrm{OH}^{-} \\
& \mathrm{Zn}+y \mathrm{OH}^{-} \rightarrow \mathrm{Zn}(\mathrm{OH})_{\mathrm{y}}+y \mathrm{e}^{-}
\end{aligned}
$$

The amount of charge stored in the battery is proportional to the number of moles of the electrochemically active material in the cathode and anode. The theoretical capacity of battery materials is usually not achieved, because parts of the materials become electrically isolated during cell operation and reaction byproducts can increase the cell resistance. The battery discharge rate is also a function of the electrical conductivity of the cathode, anode and electrolyte plus the cell design (the interfacial area of the cathode and anode, the separator thickness, etc.).

Batteries are used for applications requiring high energy (Watt-hours). When rapid discharge is needed, for instance for pulsed power applications, batteries with semiconducting cathodes can be inefficient, because polarization losses occur when the drain is higher than the discharge-rate of the battery. Ultracapacitors with metallically conducting oxides, such as 
hydrous $\mathrm{RuO}_{2}$ and $\mathrm{IrO}_{2}$, are viable alternatives and can deliver high power (Watts) [2,3]. Hydrous $\mathrm{RuO}_{2}\left(\mathrm{RuO}_{2} \cdot x \mathrm{H}_{2} \mathrm{O}\right.$ or $\left.\mathrm{RuO}_{\mathrm{x}} \mathrm{H}_{\mathrm{y}}\right)$ has been studied extensively as a pseudocapacitive charge-storage material. It exhibits a maximum specific capacity of 700 to $800 \mathrm{~F} / \mathrm{g}$ when annealed near $150{ }^{\circ} \mathrm{C}$ and has the composition: $\mathrm{RuO}_{2} \cdot 0.5 \mathrm{~mol} \mathrm{H}_{2} \mathrm{O}[4,5]$. The charge storage occurs via the "double insertion" of protons and electrons into the $\mathrm{RuO}_{2} \cdot \mathrm{xH}_{2} \mathrm{O}$ structure (Eq. 3), which is accommodated by reversible changes in the average Ru oxidation state between $4^{+}$and $2^{+}$.

$$
\mathrm{RuO}_{\mathrm{x}}(\mathrm{OH})_{\mathrm{y}}+\delta \mathrm{H}^{+}+\delta \mathrm{e}^{-} \rightleftarrows \mathrm{RuO}_{\mathrm{x}-\delta}(\mathrm{OH})_{\mathrm{y}+\delta}
$$

The composition of the positive and negative electrodes in hydrous $\mathrm{RuO}_{2}$ ultracapacitors can be identical. Whereas the semiconducting charge-storage oxides hold a fixed potential during discharge, the potential of metallic $\mathrm{RuO}_{2} \cdot x \mathrm{H}_{2} \mathrm{O}$ varies linearly with changes in the average $\mathrm{Ru}$ charge state, as reflected in its Fermi level.

\section{Batteries as micropower sources}

Several types of micropower sources are under development, but batteries are still likely to be either the sole power source or a component in a hybrid power source for new electronics systems. The disadvantage of using batteries as micropower sources is that the power and energy of batteries scale with the moles of active material in the electrodes (Eqs. 1-3), so small batteries can only deliver low levels of energy. Batteries also have relatively low energy densities compared to those promised by fuel cells or engines. The advantage of batteries is that their chemistry is fairly well understood, and no major scientific breakthroughs are necessary for their implementation. Batteries are also less hazardous as they become smaller, because issues such as runaway heating are minimized. Because batteries have a minimal heat signature, generate no noise, and have no moving parts, they cause little physical disruption to microelectronics systems.

Another advantage of using microbatteries for micropower sources is the promise of direct integration into electronic components. The battery packaging, current collectors and interconnects are readily compatible with most electronics circuits. A battery incorporated into an electronics circuit saves weight by using the electronics substrate as the battery packaging. Co-locating the battery with electronic components also reduces the weight of and ohmic losses along interconnects.

The $\mu \mathrm{W}$ to $\mathrm{mW}$ power of microbatteries matches well to that of solar and radio frequency energies, making them well suited as charge-storage media for energy-harvesting systems. An example of a solar energy-harvesting system with hybrid charge storage is shown in Fig. 2. The solar cell collects low energy over a long period of time, and the power is stored in both a secondary (rechargeable) lithium battery and ultracapacitors integrated in a simple circuit with diodes and resistor. The battery is discharged when solar energy is not available for lowpower/high-energy operation of a device. Similarly, the ultracapacitors are discharged on highpower demand to provide load leveling for optimal systems operation. A goal for this hybrid energy-harvesting system is to fabricate the micropower system directly on the back of the solar cell to economize the system weight and volume and create a high energy-density micropower system for long-term autonomous operation. 


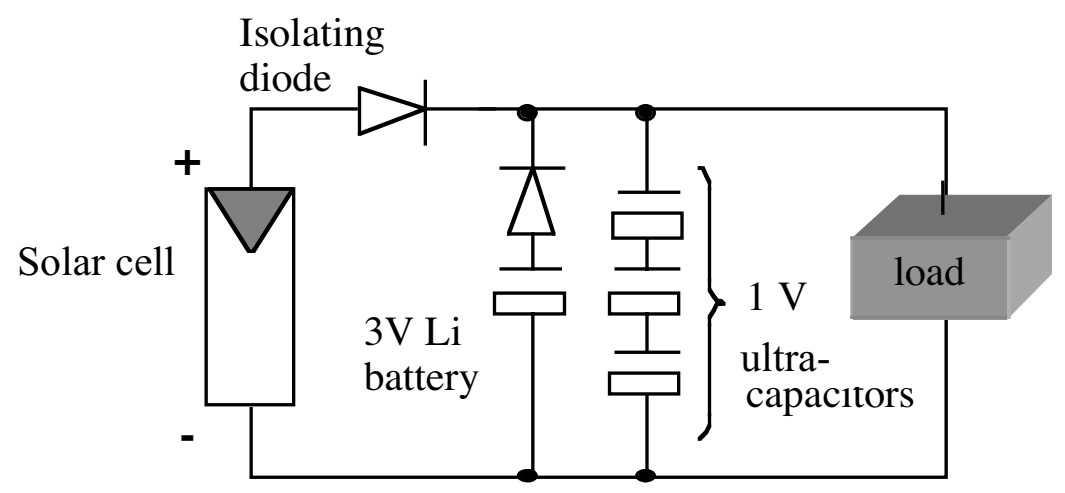

Figure 2. Schematic hybrid energy-harvesting system depicting a solar cell for energy harvesting and a lithium battery and ultracapacitors for hybrid charge storage and charge delivery. The Li battery and ultracapacitors provide energy and power, respectively, to a load. The batteries, ultracapacitors, diodes, and passive electronic components may be integrated on the back of the solar cell to conserve space and weight in an integrated microbattery system.

\section{Direct-write microbatteries}

The fabrication methods for microbatteries are another major challenge, especially in cases where the battery will be integrated into the electronics component. The high-energy thin-film "LiPON" lithium-ion batteries developed at Oak Ridge National Laboratory are manufactured using magnetron sputtering [6], therefore limiting the materials systems and substrates to those that can withstand vacuum processing. Other methods reported for microbattery fabrication include direct-write processes, such as screen printing and ink-jet methods [7]. Direct-write processes are attractive for microbattery fabrication, because they can be used to deposit the polymers, oxides and metals used in batteries and are not restricted to vacuum conditions, making feasible the deposition of corrosive electrolytes and hydrous materials.

We demonstrate in this manuscript a new process for microbattery fabrication and systems integration, the MAPLE DW (Matrix-Assisted Pulsed-Laser Evaporation Direct Write) process. MAPLE DW was developed at the Naval Research Laboratory primarily for the fabrication of conformal, mesoscale (1 $\mu \mathrm{m}$ to $1 \mathrm{~mm}$ ) passive electronic components [7-10], but it has many clear advantages for battery fabrication. The procedures for MAPLE DW processing are summarized schematically in Fig. 3 for the fabrication of an alkaline battery $\mathrm{MnO}_{2}$ cathode, but this general process is applicable for all materials and for multiple layers. The target material is mixed with a viscous vehicle (e.g., an organic liquid such as ethylene glycol) to form an ink (Fig. 3a) that is cast as a 1- to 10- $\mu$ m-thick film onto an ultraviolet (UV)-transparent substrate to create a "ribbon" (Fig. 3b). A pulsed UV-laser $(355 \mathrm{~nm})$ forward transfers the ink from the ribbon onto a desired substrate under ambient pressure and temperature conditions (Fig. $3 \mathrm{c}$ ). The amount of material transferred is a function of the laser fluence, laser spot size (10 to $100 \mu \mathrm{m}$ diameter), and ink thickness. MAPLE DW can be envisioned as a "laser typewriter," because the substrate moves on a computer-controlled translation stage underneath the laser and ribbon allowing the fabrication of high-resolution $(20 \mu \mathrm{m})$ intricate designs. Subsequent laser micromachining can also be used to modify the design of the transferred material or the substrate for systems integration (Fig. 3d). The transferred material can be post-processed to remove the 
residual vehicle, sinter the film, and adhere the film to the substrate either using conventional heating methods or laser annealing.

Because MAPLE DW can be carried out under ambient conditions, it is amenable to most battery chemistries. Hydrous $\mathrm{RuO}_{2}$ ultracapacitor power sources can be processed below $170{ }^{\circ} \mathrm{C}$ and achieve maximum performance [4,5]. Similarly, electrolytic $\mathrm{MnO}_{2}$ is not deleteriously dehydrated during fabrication and processing with MAPLE DW. The moisture-sensitive materials for Li batteries can be handled simply by engulfing the ribbon and substrate in a dry bag.

Another advantage of the MAPLE DW process is the CAD/CAM features which allow the rapid prototyping necessary for device optimization. For instance, the battery design can be easily reconfigured to alter the battery discharge profile and match a desired power demand. MAPLE DW also has been used successfully to transfer all the components needed for battery systems, including metal interconnects, multilayer capacitors, inductors, and resistors [7-10], to ultimately expedite the fabrication of complete battery systems. The process is also not limited to flat surfaces, enabling the deposition of batteries onto unconventional substrates.

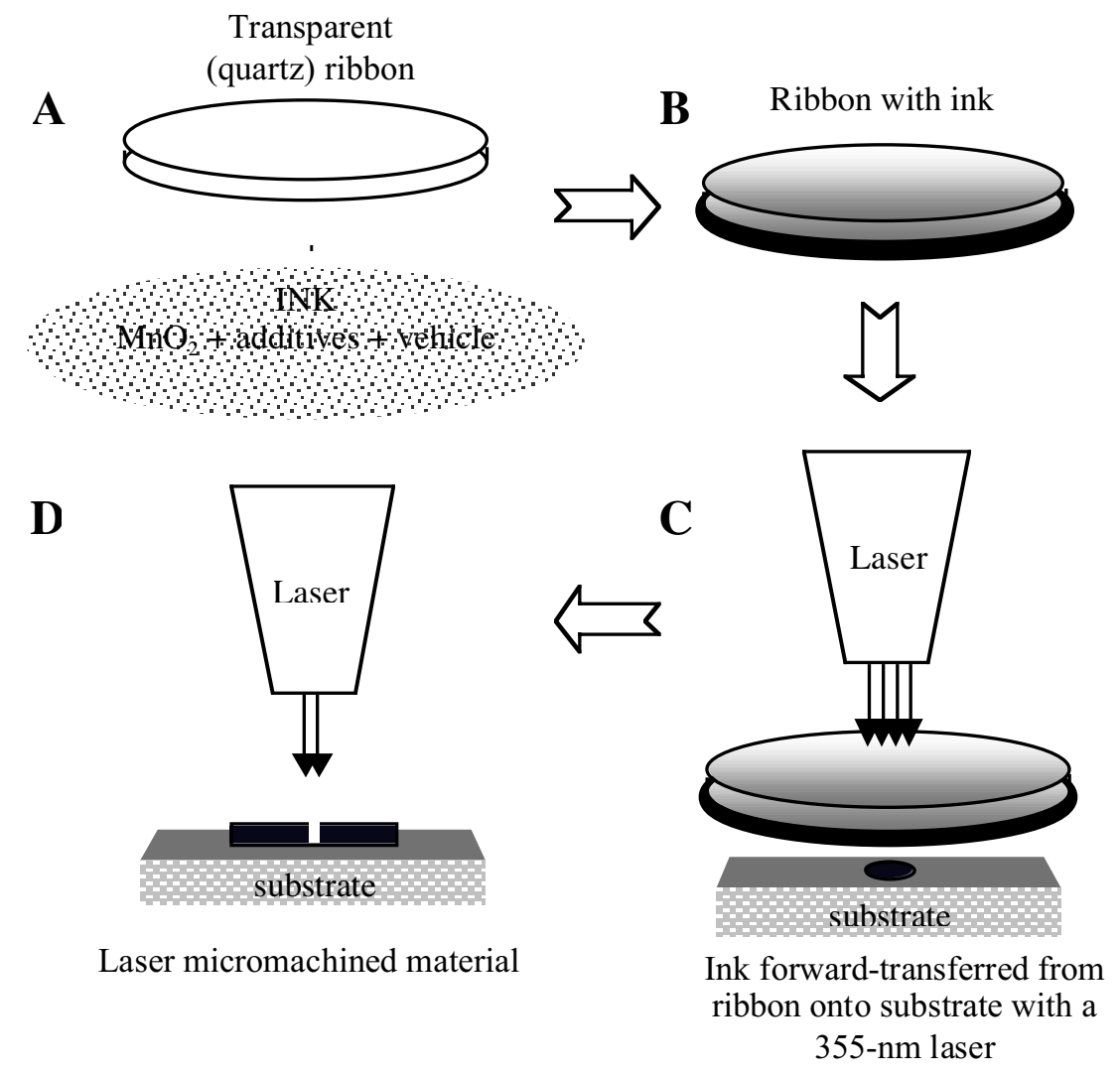

Figure 3. MAPLE DW fabrication of an alkaline battery $\mathrm{MnO}_{2}$ cathode. (A) an ink is prepared from electrolytic $\mathrm{MnO}_{2}$, carbon, a binder, and a vehicle; (B) the ink is tape cast onto a transparent "ribbon"; (C) the UV-laser forward transfers the ink from the ribbon onto an appropriate substrate; and (D) laser processing is used to micromachine and/or laser anneal the $\mathrm{MnO}_{2}$ pad. Subsequent processing is used to remove residual vehicle, as necessary. 


\section{EXPERIMENTAL DETAILS}

The MAPLE DW fabrication of an alkaline battery and planar $\mathrm{RuO}_{2} \bullet x \mathrm{H}_{2} \mathrm{O}$ ultracapacitors has already been described elsewhere in detail $[11,12]$.

Briefly, for the MAPLE DW of $\mathrm{RuO}_{2} \bullet x \mathrm{H}_{2} \mathrm{O}$ ultracapacitors, an ink consisting of commercial $\mathrm{RuO}_{2} \cdot 0.5 \mathrm{H}_{2} \mathrm{O}\left(150^{\circ} \mathrm{C}\right.$-annealed material from Alfa) and a vehicle (ethylene glycol, glycerin and/or sulfuric acid) is applied to fused-silica discs using a wire roller to form the ribbon. The $\mathrm{RuO}_{2} \cdot 0.5 \mathrm{H}_{2} \mathrm{O}$ ink is forward-transferred by MAPLE DW as pads onto either $1-\mathrm{cm}^{2}$ gold-coated glass or carbon-foil substrates. The pads are micromachined with gaps of varying length and width in order to fabricate cell structures with different interface characteristics, and then they are heated to remove any residual vehicle. Electrochemical evaluation is carried out either on the $\mathrm{RuO}_{2} \bullet x \mathrm{H}_{2} \mathrm{O}$ pads submerged in $0.5 \mathrm{M} \mathrm{H}_{2} \mathrm{SO}_{4}$ or after adding a drop of $5 \%$ Nafion solution (Aldrich), which is air dried to serve as a solid-state electrolyte.

The positive electrodes of the $\mathrm{Zn} / \mathrm{MnO}_{2}$ alkaline batteries are fabricated from inks of electrolytic $\mathrm{MnO}_{2}$ (JEC) mixed with acetylene carbon black (Alfa), PVDF (Elf-Atochem), an organic vehicle, and concentrated $\mathrm{KOH}$. The inks are cast as ribbons as described above for the $\mathrm{RuO}_{2} \bullet x \mathrm{H}_{2} \mathrm{O}$ materials. A $\mathrm{MnO}_{2}$ pad is deposited from a ribbon onto an appropriate substrate with MAPLE DW. A layer of ethyl cellulose (Aldrich) and a layer of Nafion are drop cast over the $\mathrm{MnO}_{2}$ pad to serve as the separator. An ink of $\mathrm{Zn}$ powder (GoodFellow), an organic vehicle and concentrated $\mathrm{KOH}$ is forward-transferred with MAPLE DW on top of the separator. The multilayer structure is heated to remove any organic residue and then discharged.

The chronopotentiometry of the ultracapacitors and batteries is evaluated using an EG\&G PAR 263 potentiostat controlled with M270 software. The morphology of the battery and ultracapacitor pads is surveyed with optical microscopy and scanning electron microscopy (SEM, Leo 1550), and the thickness of both the ink ribbons and the dried pads are determined via stylus profilometry (Tencor P10).

\section{RESULTS}

\section{$\underline{\mathrm{RuO}}_{2}$ ultracapacitors}

Hydrous $\mathrm{RuO}_{2}$ pads deposited with MAPLE DW are uniformly deposited from inks containing ethylene glycol, glycerol, and/or sulfuric acid vehicles. Fig. 4a shows an as-deposited $\mathrm{RuO}_{2} \cdot 0.5 \mathrm{H}_{2} \mathrm{O}$ pad $\left(1000 \mu \mathrm{m}^{2} \times 5 \mu \mathrm{m}\right)$ on a glass slide. The pad is subsequently micromachined into four separate pads (Fig. 4b) for use as two planar ultracapacitor cells. Figure 4c shows the excellent resolution of pads machined with $18 \mu \mathrm{m}$-wide lines. After heating to remove the residual vehicle, the pads weigh less than $1 \mathrm{mg}$.

Electrochemical evaluation of the hydrous $\mathrm{RuO}_{2}$ pads indicates that they have excellent electrochemical properties [13]. When the appropriate deposition and post-annealing conditions are used, the capacitance of the pads on graphite foil is equivalent to that reported for bulk $\mathrm{RuO}_{2} \bullet 0.5 \mathrm{H}_{2} \mathrm{O}(\sim 700$ to $800 \mathrm{~F} / \mathrm{g})$, as measured with cyclic voltammetry. The discharge profiles of cells deposited on gold-coated glass have energy and power densities comparable to that reported in the literature $[1,3]$. Their performance is affected by the presence of a binder, and the highest charge storage is achieved when the pads are encapsulated in Nafion. Two cells (4 pads) linked in parallel or in series yield doubled capacities and potentials, respectively [11,13], indicating that the laser-machined lines allow uniform discharge of the cells. 

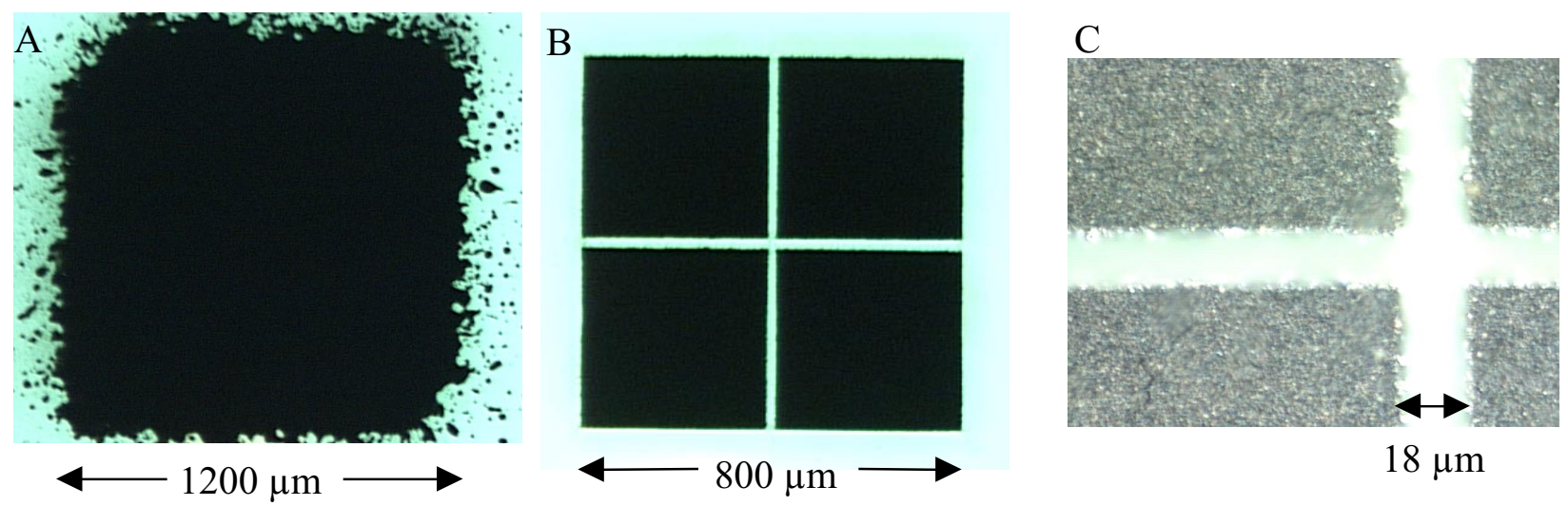

Figure 4. Optical micrographs of $\mathrm{RuO}_{2}$ pads deposited with MAPLE DW. (A) as-deposited single pad, (B) pad that has been laser micromachined into 4 pads for use as 2 ultracapacitor cells, and (C) high magnification photo showing the high resolution of laser micromachining.

\section{$\underline{\text { Alkaline batteries }}$}

An example of a stacked alkaline microbattery fabricated with MAPLE DW is shown in Fig. 5. A $2 \times 3 \mathrm{~mm}^{2}$ pad of an electrolytic- $\mathrm{MnO}_{2}$ composite (including carbon, a binder, and $\mathrm{KOH}$ ) is in contact with a gold-coated glass substrate. The $\mathrm{MnO}_{2}$ pad is covered with a $4 \times 5 \mathrm{~mm}^{2}$ pad of ethyl cellulose and $2 \times 3 \mathrm{~mm}^{2}$ pad of $\mathrm{Zn}$ (Fig. 5a). We have also successfully fabricated stacked alkaline microbatteries in which the top $\mathrm{Zn}$ layer overlays the electrolyte and is in contact with the bottom electrode [12].

With the removal of residual vehicle, these microbatteries have the expected cell voltage of $1.5 \mathrm{~V}$ and can power a digital watch for over $10 \mathrm{~min}$ (Fig. 5b). The specific energy of these batteries is approximately ten times lower than expected, due to the high resistance of the ethyl cellulose separator. Next steps to increasing their specific energy include lowering the resistance of the separator layer and optimizing the processing conditions.
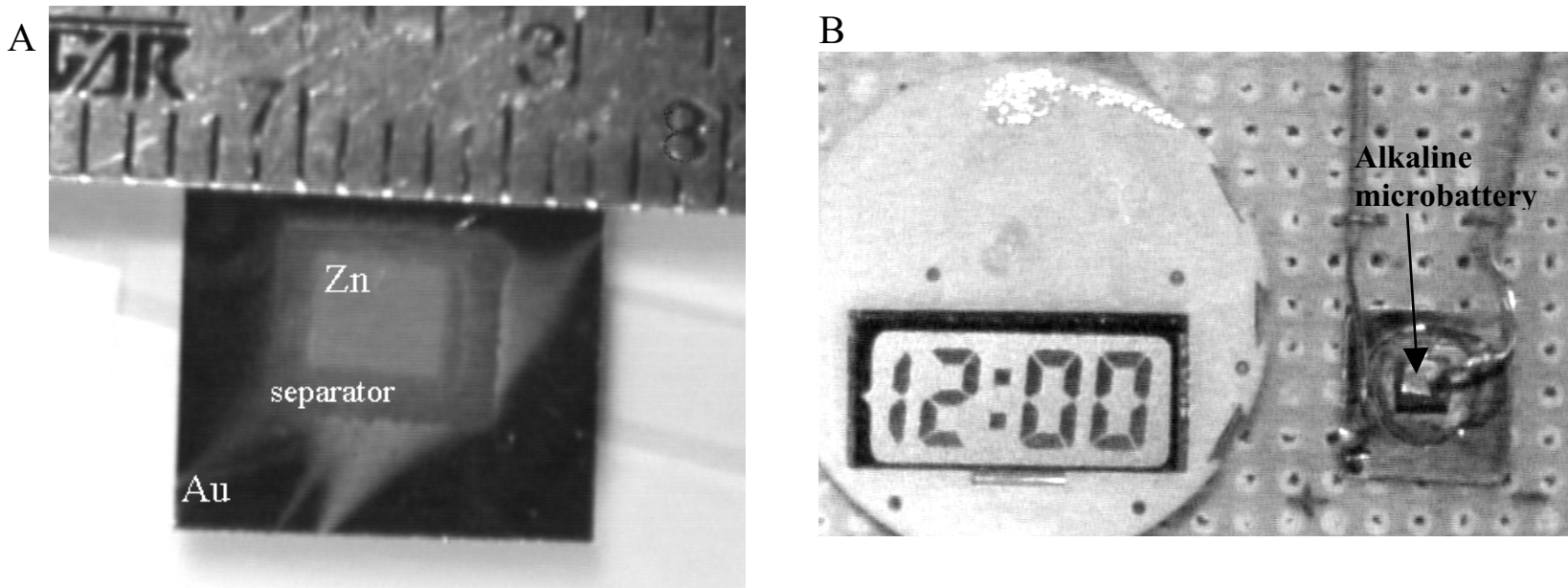

Figure 5. Optical micrographs of (A) a stacked alkaline microbattery fabricated with MAPLE $\mathrm{DW}$, where the $\mathrm{MnO}_{2}$ positive electrode (not visible) is underneath the $\mathrm{Zn}$ pad and separator; and (B) the alkaline microbattery providing power to a digital watch. 


\section{CONCLUSIONS}

Microbatteries are likely to be the sole power source or part of a hybrid power source in the next generation of microelectronic devices. Although microbatteries offer limited energy, their chemistry and properties are well understood, and they will provide efficient power systems when fully integrated into electronic devices. Rechargeable microbatteries coupled with energy harvesting systems can be used for applications requiring long-term autonomous operation. Hybrid power sources of batteries and ultracapacitors can be used to efficiently power devices having both high and low power demands.

The LEAPS program leverages the MAPLE DW forward-transfer laser process to fabricate and integrate microbattery systems. MAPLE DW offers many opportunities for microbattery fabrication, because it can be used to nondestructively deposit hydrated and defective powders, polymers, and metals. The lack of materials restrictions allows a broad platform of battery systems (e.g., alkaline, lithium, ultracapacitors) to be developed. The CAD/CAM features of MAPLE DW can be utilized to rapidly vary and optimize the design of the batteries, plus build series or parallel battery arrays to meet a desired power demand. It can also be used to fabricate the passive electronic components needed for complete microbattery systems.

The evaluation of planar $\mathrm{RuO}_{2}$ ultracapacitors demonstrates that MAPLE DW can be used to make cells with repeatable performance. Laser processing allows battery components to be laser micromachined with uniform interfaces and into different geometries. The cell performance scales when the cells are linked in series and parallel. However, processing conditions and cell geometry must still be optimized to achieve high power direct-write ultracapacitors.

The demonstration of stacked alkaline microbatteries indicates that layers can be added vertically with MAPLE DW without electronic shorting. The microbattery performance is most affected by the choice of battery materials and processing conditions.

Many challenges remain in the development of direct-write electrochemical power sources, particularly in the optimization of the cell capacities. Application of current collectors and packaging is still needed before our ultracapacitors and microbatteries can be fully integrated into microelectronic circuits. Other power sources in development include secondary lithium-ion batteries.

\section{ACKNOWLEDGEMENTS}

The authors are grateful to the Office of Naval Research for support of the LEAPS program. CBA is a National Research Council postdoctoral fellow, and RCW is an American Association for Engineering Education postdoctoral fellow.

\section{REFERENCES}

1. C. A. Vincent and B. Scrosati, Modern Batteries: An Introduction to Electrochemical Power Sources, $2^{\text {nd }}$ ed. (John Wiley \& Sons, New York, 1997).

2. B. E. Conway, J. Electrochem. Soc., 138, 1539 (1991).

3. S. Trasatti, Electrochim. Acta, 36, 225 (1991).

4. J. P. Zheng, P. J. Cygan and T. R. Jow, J. Electrochem. Soc., 142, 2699 (1995). 
5. D. A. McKeown, P. L. Hagans, L. P. L. Carette, A. E. Russell, K. E. Swider and D. R. Rolison, J. Phys. Chem. B, 103, 4825 (1999).

6. J. B. Bates, N. J. Dudney, B. Neudecker, A. Ueda and C. D. Evans, Solid State Ionics, 135, 33 (2000).

7. A. Piqué and D. B. Chrisey, Editors, Direct-Write Technologies for Rapid Prototyping Applications (Academic Press, San Diego, 2002).

8. A. Piqué, D. B. Chrisey, R. C. Y. Auyeung, J. Fitz-Gerald, H. D. Wu, R. A. McGill, S. Lakeou, P. K. Wu, V. Nguyen and M. Duignan, Appl. Phys. A, 69 [Suppl.], S279 (1999).

9. D. B. Chrisey, A. Piqué, J. Fitz-Gerald, B. Ringeisen and R. Modi, Laser Focus World, 113 (2000).

10. D. B. Chrisey, R. A. McGill and A. Piqué, U.S. Patent No. 6,177,151 (23 January 2001).

11. K. E. Swider-Lyons, D. W. Weir, C. T. Love, R. Modi, T. Sutto, A. Piqué and D. B. Chrisey, in Power Sources for the New Millennium, edited by M. Jain, M. A. Ryan, S. Surampudi, R. A. Marsh and G. Nagarajan (Electrochem. Soc. Proc. 2000-22, Pennington, NJ, 2000) pp. 272-276.

12. A. Piqué, K. E. Swider-Lyons, D. W. Weir, C. T. Love and R. Modi, in Laser Applications in Microelectronic and Optoelectronic Manufacturing VI, edited by M. C. Gower, et. al. (SPIE Proc. 274, Bellingham, WA, 2001) pp. 316-322.

13. C. B. Arnold, R. C. Wartena, A. Piqué and K. E. Swider-Lyons, in Rapid Prototyping Technologies - Tissue Engineering to Conformal Electronics, edited by D.B. Chrisey, et. al. (Mater. Res. Proc., Pittsburgh, PA, 2001) in press. 